\title{
An Analysis of ESR2 and CYP19A1 Gene Expression Levels in Women With Endometriosis
}

\author{
TOMASZ SZAFLIK ${ }^{1 *}$, BEATA SMOLARZ $^{2 *}$, BEATA MROCZKOWSKA $^{1}$, BARTOSZ KULIG $^{1}$, MALWINA SOJA ${ }^{1}$, \\ HANNA ROMANOWICZ ${ }^{2}$, MAGDALENA BRYŚ ${ }^{3}$, EWA FORMA $^{3}$ and KRZYSZTOF SZYŁŁO ${ }^{1}$ \\ ${ }^{1}$ Department of Operative Gynaecology and Oncological Gynaecology, \\ Polish Mother's Memorial Hospital Research Institute, Lodz, Poland; \\ ${ }^{2}$ Laboratory of Cancer Genetics, Department of Pathology, \\ Polish Mother's Memorial Hospital Research Institute, Lodz, Poland; \\ ${ }^{3}$ Department of Cytobiochemistry, Faculty of Biology and Environmental Protection, \\ University of Lodz, Lodz, Poland
}

\begin{abstract}
Aim: The analysis of oestrogen receptor (ESR2) and cytochrome P450 family 19 subfamily A member (CYP19A1) gene expression in the context of the risk for endometriosis development. Materials and Methods: Tissue specimens, collected from patients with endometriosis $(n=100)$ and from control patients $(n=100)$ embedded into paraffin blocks, provided the material for genetic studies, oriented towards the expression of ESR2 and CYP19A1 genes. The gene expression was assessed by the reverse transcription-polymerase chain reaction technique. Results: Higher expression levels of ESR2 gene were demonstrated in the patients with endometriosis in comparison with the healthy controls. The expression intensity of CYP19Al gene was associated with endometriosis, manifested as abdominal wall nodules. A relationship was observed between CYP19A1 gene expression and the Revised American Society for Reproductive Medicine classification in the group with ovarian endometrioid cysts, as well as in the group with peritoneal endometriosis. Conclusion: This study suggests the significant role of ESR2 and CYP19A1 gene expression in the pathogenesis of endometriosis.
\end{abstract}

Endometriosis is a frequent gynaecological condition, both in Poland and worldwide (1) and is defined as the occurrence of

This article is freely accessible online.

$*$ These Authors contributed equally to this study and should be
regarded as joint first Authors.

Correspondence to: Beata Smolarz, Laboratory of Cancer Genetics, Department of Pathology, Institute of Polish Mother's Memorial Hospital, Lodz, Poland, Rzgowska 281/289, 93-338 Lodz, Poland. Tel: +48 422711290, e-mail: smolbea@wp.pl

Key Words: CYP19A1, ESR2, expression, endometriosis. uterine mucosa beyond the uterine cavity with a concomitant and chronic inflammatory condition. This disease affects $10-$ $15 \%$ of women of reproductive age and $35-50 \%$ of women with pain in the pelvis minor or with infertility. One should keep in mind, however, that sporadic cases of endometriosis are also diagnosed in patients after menopause, as well as in young women. No specific marker for endometriosis has yet been identified. Groups of compounds are now searched for which, in a specific combination, would ensure maximum sensitivity and specificity of non-invasive diagnostics for this disease, especially in its early stages $(3,4)$.

Endometriosis is an oestrogen-dependent disease. It presents a specific ability to receive oestrogen stimulation of its development. An enhanced local production of oestrogens takes place within endometrial tissue as a result of increased expression of the $\mathrm{P} 450$ cytochrome aromatase. The product of the CYP19A1 gene, aromatase converts testosterone and androstenedione into oestradiol and oestrone, respectively (5). Endometriosis lesions, unlike eutopic endometrium, demonstrate some activity of the aromatase (6).

The action of oestrogens on target cells is possible via oestrogen receptors, which act as transcriptive factors, and plays a significant role in the growth and differentiation of endometrial cells, as well as in numerous biological functions, in both, eutopic and ectopic endometrium. The two types of oestrogen receptors thus far identified are ER $\alpha$ and ER $\beta$, encoded by two different genes (ESR1 and ESR2, respectively). ER $\beta$ is the main oestrogen receptor in patients with endometriosis $(7,8)$.

A higher expression of $\mathrm{P} 450$ cytochrome and of hydroxysteroid 17-dehydrogenase in ectopic endometrium increases the oestrogen level, which activates endothelial cells of the stroma and brings about the development of endometriosis $(9,10)$. This study aimed to determine whether there were any correlations between the gene 
Table I. Characteristic features of patients with endometriosis and of the controls.

\begin{tabular}{lcc}
\hline & $\begin{array}{c}\text { Study group } \\
(\mathrm{n}=100)\end{array}$ & $\begin{array}{c}\text { Control group } \\
(\mathrm{n}=100)\end{array}$ \\
\hline $\begin{array}{l}\text { Age, years } \\
\text { Mean } \pm \text { SD (range) }\end{array}$ & $34.89 \pm 7.49(21-53)$ & $47.93 \pm 6.01(26-67)$ \\
BMI, $\mathrm{n}(\%)$ & $68(68 \%)$ & $29(29 \%)$ \\
$<25 \mathrm{~kg} / \mathrm{m}^{2}$ & $22(22 \%)$ & $43(43 \%)$ \\
$25 \leq \mathrm{BMI}<30 \mathrm{~kg} / \mathrm{m}^{2}$ & $10(10 \%)$ & $28(28 \%)$ \\
$\geq 30 \mathrm{~kg} / \mathrm{m}^{2}$ & & \\
$\begin{array}{l}\text { Deliveries, } \mathrm{n}(\%) \\
0\end{array}$ & $53(53 \%)$ & $7(7 \%)$ \\
1 & $21(21 \%)$ & $36(36 \%)$ \\
$\geq 2$ & $26(26 \%)$ & $57(57 \%)$ \\
Spontaneous abortion, $\mathrm{n}(\%)$ & $5(5 \%)$ & $9(9 \%)$ \\
Yes & $95(95 \%)$ & $91(91 \%)$ \\
No & & \\
\hline
\end{tabular}

BMI: Body mass index; SD: standard deviation.

expression of ESR2 and CYP19A1 and the incidence of endometriosis. ESR2 and CYP19A1 genes were selected for the study due to their considerable role in hormonal control, in patients with endometriosis, the development of which is largely determined by steroid hormones (10-13).

The goals of the study included: a) An analysis of ESR2 and CYP19A1 gene expression levels in patients with endometriosis and in a control group; b) analysis of correlation of the levels of ESR2 and CYP19A1 gene expression with clinicopathological data; and c) the assessment of the significance of obtained results in the context of the risk for endometriosis.

\section{Materials and Methods}

Patients. Tissue specimens, collected from patients with endometriosis $(n=100)$ and from control patients $(n=100)$, embedded in paraffin blocks, provided the material for studies. The paraffin blocks were provided by the Archive of the Department of Clinical Pathomorphology, Institute-Polish Mother's Memorial Hospital in Lodz, Poland.

The study group comprised 100 patients who underwent surgery for endometriosis at the Department of Operative Gynaecology and Oncological Gynaecology of the Institute - Polish Mother's Memorial Hospital in Lodz, during the years 2015-2016. Endometriosis was confirmed by intraoperative diagnostics and, finally, by histopathological evaluation. See Table I for characteristic features of the patients.

The study material included the following specimens: 63 cases of endometrial ovarian cyst, 10 cases of endometriosis nodules from abdominal walls, 17 cases of peritoneal endometriosis, 10 cases of deeply infiltrating endometriosis. The clinical staging was carried out in the patients using the 1996 Revised American Society for Reproductive Medicine classification of endometriosis (rASRM; Table II) (14).

The control group consisted of 100 patients from the Department of Operative Gynaecology and Oncological Gynaecology of the Institute-Polish Mother's Memorial Hospital in Lodz, Poland.
Table II. The clinical staging of patients with endometriosis $(n=100)$ by the Revised American Society for Reproductive Medicine classification of endometriosis (14).

\begin{tabular}{lc}
\hline Clinical stage & Frequency (\%) \\
\hline I & $26(26 \%)$ \\
II & $25(25 \%)$ \\
III & $17(17 \%)$ \\
IV & $32(32 \%)$ \\
\hline
\end{tabular}

Histopathological assessments confirmed normal endometrium in all the controls. The control patients had not suffered from endometriosis. The specimens collected during surgery were immediately cooled to $-20^{\circ} \mathrm{C}$ and then stored for further analysis at a temperature of $-70^{\circ} \mathrm{C}$. All the specimens were histologically characterised. Formal consent (No. 8/2016) for this study was obtained from the Bioethical Committee of the Institute-Polish Mother's Memorial Hospital in Lodz.

RNA isolation. Total RNA was isolated with the Trizol reagent (Ambion, Austin, TX, USA). RNA samples were stored in the temperature of $-20^{\circ} \mathrm{C}$. Isolated RNA was usually stored for no more than $24-48$ hours. This time did not affect the quality or integrity of the RNA.

Spectrophotometric analysis of RNA purity and concentration. The purity of obtained RNA specimens was evaluated by the spectrophotometric method, employing a two-fold absorbance measurement of each sample at $260 \mathrm{~nm}$ and $280 \mathrm{~nm}$ wavelength. A260/A280 values between 1.8 and 2.0 were accepted as criteria for RNA purity. RNA concentrations were measured by spectrophotometric method, based on the absorbance value (OD), measured at $260 \mathrm{~nm}$. That value corresponded to the following relationship: 1 unit $\mathrm{OD}=40$ $\mu \mathrm{g} \mathrm{DNA} / \mathrm{ml}$. The mean RNA concentrations and purity degree obtained for the study material met the necessary criteria.

Reverse transcription polymerase chain reaction (RT-PCR). A reverse transcription reaction was carried out using a TaKaRa RNA PCR kit (AMV) ver 3.0 (Takara Bio Inc., Tokyo, Japan). The obtained cDNA samples were stored at $-20^{\circ} \mathrm{C}$. According to the manufacturer's instructions, the amount of RNA was about $500 \mathrm{ng}$.

PCR with an analysis of product volume growth in real time. The reaction mixture included $0.5 \mu \mathrm{l}$ of cDNA, $0.5 \mu \mathrm{l}$ of $20 \times \mathrm{TaqMan}{ }^{\circledR}$ Gene Expression Assay (Applied Biosystems, Foster City, CA, USA), $5 \mu$ l of TaqMan ${ }^{\circledR}$ Universal PCR MasterMix (Applied Biosystems), containing TaqMan ${ }^{\circledR}$ DNA polymerase, dNTP, a reaction buffer and $4 \mu \mathrm{l}$ of water. Real-Time PCR was carried out in a Mastercycler ${ }^{\circledR}$ ep realplex device (Eppendorf, Germany). The thermal profile of the reaction included a preliminary denaturation in the temperature of $95^{\circ} \mathrm{C}$ for 10 minutes, followed by 50 cycles of 15 -second incubation at $95^{\circ} \mathrm{C}$, combined with 1 minute at $60^{\circ} \mathrm{C}$. The following, commercially available kits of probes and starters were applied in the real-time PCR: Hs01100353_m1 for ESR2 gene, Hs00903411_m1 for CYP19A1 gene and Hs02800695_m1 for hypoxanthine phosphoribosyltransferase 1 (HPRT1) gene, being a reference gene. The obtained $\mathrm{Ct}$ values were recalculated to the number of mRNA copies of the studied gene per 1,000 mRNA copies of HPRT1, according to the following correlations: 


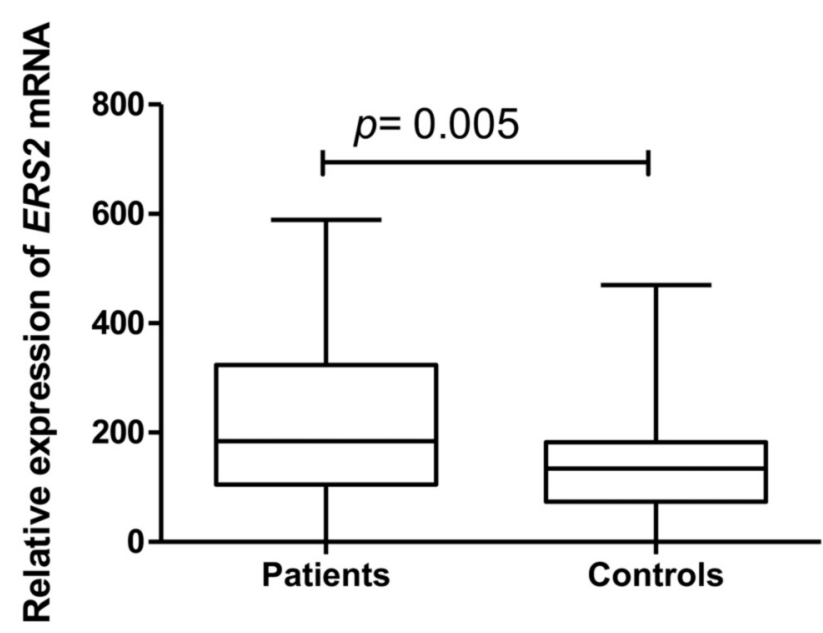

Figure 1. Relative oestrogen receptor $\beta$ (ESR2) gene expression in study groups. where $\mathrm{L}$ was the number of mRNA copies of the study gene per 1,000 copies of the reference gene mRNA. The mean Ct values, obtained for both neoplastic and normal material, met the necessary criteria.

Statistical analysis. The obtained results were statistically processed by means of the STATISTICA 11 software (StatSoft, Poznan, Poland). The significance of differences was analysed at the level of gene expression and mRNA, using non-parametric tests (the $U$ Mann-Whitney test and the Kruskal-Wallis test) for a lack of distribution normality of the obtained results, as confirmed by the Shapiro-Wilk test. The Spearman rank-order correlation coefficient test was used to assess correlations between variables. A statistical significance was confirmed at $p<0.05$.

\section{Results}

The study demonstrated higher expression of ESR2 gene in 100 examined patients with endometriosis in comparison with the healthy controls (Figure 1). The ESR2 gene expression in the study group did not correlate with the age of the patients nor with their body mass index, the level of cancer antigen125 (CA125) marker nor with the number of previous pregnancies. No relationship was revealed between ESR2 gene expression and rASRM classification scores in the study group. Neither were any relationships demonstrated between the ESR2 gene expression level and the clinicopathological factors when the patients were classified to the particular types of endometriosis, such as: peritoneal, deeply infiltrating or endometrial ovarian cysts. Only in the case of endometrial nodules in abdominal walls, was ESR2 gene expression significantly higher compared with the control group.

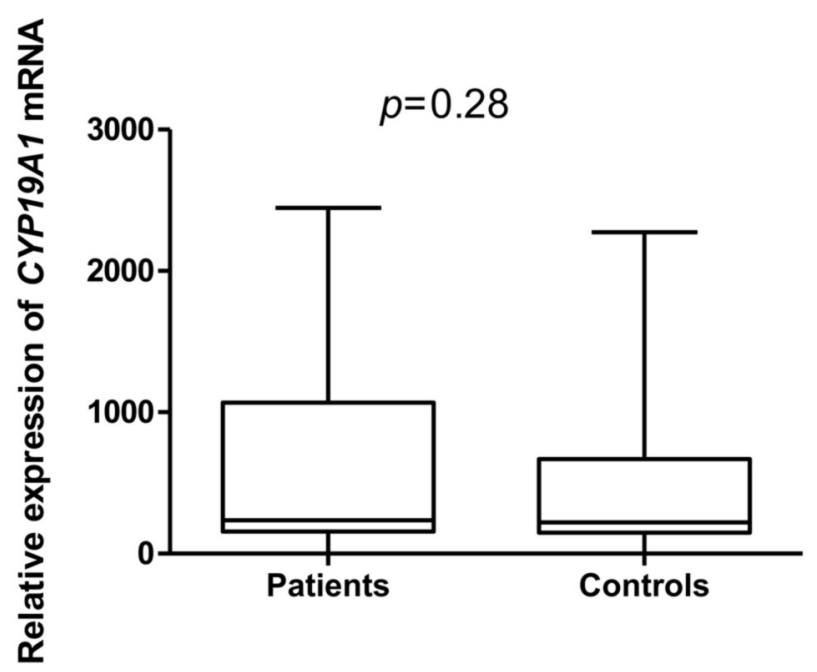

Figure 2. Relative gene expression of cytochrome P450 family 19 subfamily A member (CYP19A1) in study groups.

Regarding CYP19A1 gene in the study, no correlation with endometriosis was identified in the study group $(n=100)$ (Figure 2).

However, negative correlation was confirmed between CYP19A1 gene expression level and body mass index (Figure 3 ). The expression of the $C Y P 19 A 1$ gene showed a statistically significant relationship with the level of CA125 marker in the patient group (Table III); expression was higher in the group with a concentration of CA125<35 U/ml (Figure 4).

The CYP19A1 gene expression intensity was associated with endometriosis nodules of the abdominal wall. In the group of patients with endometrial ovarian cysts, a statistically significant negatively relationship was confirmed between the expression levels of CYP19A1 gene and the number of pregnancies and deliveries in those patients (Table IV). A relationship was observed between CYP19A1 gene expression and rASRM classification scores in the group with ovarian endometrioid cysts, as well as in the group with peritoneal endometriosis (Figure 5): CYP19A1 gene expression level was higher in patients with a higher degree (III-IV) of disease.

\section{Discussion}

The expression levels of ESR2 and CYP19A1 genes were assayed in patients with endometriosis and compared with a healthy control group, while also studying their association with increased prevalence of endometriosis among Polish women.

Disorders at the level of ESR2 gene expression associated with endometriosis and related to the types and sites of lesions have been confirmed by world literature reports. The team of Maekawa et al. employed RT-PCR to assay the expression levels of ESR1, ESR2 and progesterone receptor $(P G R)$ genes in cases of ovarian endometriosis and eutopic 


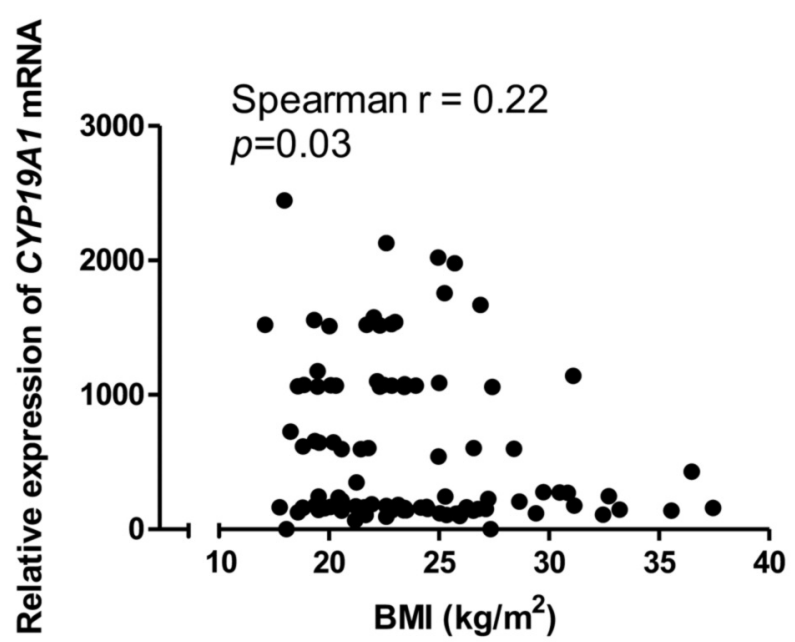

Figure 3. Correlation between body mass index (BMI) and the relative gene expression of cytochrome P450 family 19 subfamily A member (CYP19A1) for the patient group.

endometrium (15). The ESRI and PGR expression levels were substantially lower, while the level of ESR2 gene expression was significantly higher in endometriosis than in normal endometrium. DNA methylation levels were also studied. DNA methylation of ESRl gene was significantly higher in endometriosis than in eutopic endometrium. No major differences were observed in the degree of DNA methylation for ESR2 nor for PGR. The researchers made a suggestion that the observed, abnormal DNA methylation was associated with a low level of ESRI expression. While the degree of methylation did not affect the expression changes of ESR2 or PGR genes in endometriosis (15).

The latest study of the team of Yilmaz and Bulun demonstrated that endometrial stromal cells, which participate in the inflammatory process, are induced by oestrogen, and play a role in the formation of prostaglandins, revealed an extremely low ratio of ESR1 to ESR2 expression, resulting from an excessive increase in the expression of the latter gene (12). The cells also demonstrated a deficit of PGR protein, which leads to resistance to progesterone and defective retinoid synthesis. The expression of nuclear receptors, including low levels of ESRI and PGR under a high level of $E S R 2$, corresponds to the expression of factors found in the stem cells of uterine fibroid. It is suggested that endometrial stromal cells may present certain features of stem cells present in other uterine tissues.

In the study of Colon-Caraballo et al., the expression of ESR1, ESR2 and PGR was assayed in various types of endometrial change and in eutopic endometrium of women with endometriosis and in a control group (11). Changes in ovarian ducts were characterised by high expression levels of
Table III. Relative gene expression of cytochrome P450 family 19 subfamily A member (CYP19A1) with regard to level of the marker cancer antigen $C A 125$.

\begin{tabular}{lcc}
\hline & \multicolumn{2}{c}{ CA125 } \\
\cline { 2 - 3 } & $\leq 35 \mathrm{U} / \mathrm{ml}$ & $>35 \mathrm{U} / \mathrm{ml}$ \\
\hline Number of specimens & 58 & 38 \\
Mean \pm SD (range) & $642.1 \pm 618.7$ & $367.3 \pm 387.5$ \\
& $(66.67-2,446)$ & $(0.0-1,542)$ \\
\hline
\end{tabular}

Mann-Whitney test, $p=0.046$.

all three receptors. Differences observed among endometrial specimens included lower ESR 1 expression and higher ESR2 expression in the proliferative endometrium from the study group. A tendency towards a lack of nuclear activity of $P G R$ was identified in the proliferative endometrium from patients. The highest ESR2:ESR1 expression ratio was observed in those with endometrial changes of the ovaries and in the secretory endometrium. The results obtained by ColonCaraballo et al. are valuable as they extend our knowledge regarding the potential for individual reactions to hormonal therapies, providing a basis to develop personalised therapeutic methods for women with endometriosis (11).

CYP19A1 was another gene whose expression was analysed in the reported study. CYP19Al encodes cytochrome P450 aromatase, an enzyme participating in the biosynthesis of oestrogens. In regard to $C Y P 19 A 1$, the goals of the study focused on correlations between the level of gene expression and the prevalence of endometriosis, as when the study was planned there was no basis for the changes we subsequently found. The identification of variable expression levels of the aromatase-encoding gene in this study may make a significant contribution to the understanding of the mechanism responsible for the enhanced production of oestrogens observed in endometriosis.

There are literature data suggesting that the expression of CYP19A1 gene may not change in endometriosis (6), which was partially confirmed by the results of our study.

The reduced CYP19A1 expression in endometriosis may result from epigenetic modifications in the regulatory regions of the gene, for example, DNA methylation or the modification of histones (16). Changes in the methylation status of $\mathrm{CpG}$ islands, contained in CYP19A1 gene were confirmed in endometriosis by Izawa et al. (17). A CpG island is localised approximately $70 \mathrm{~kb}$ below exon 1.1 of the CYP19A1 gene. It was found to be hypomethylated in endometriosis (studies were run on stromal cells, obtained from chocolate ovarian cysts). However, its hypermethylation was found in eutopic endometrium (stromal cells obtained from women, not suffering from endometriosis) (17). 


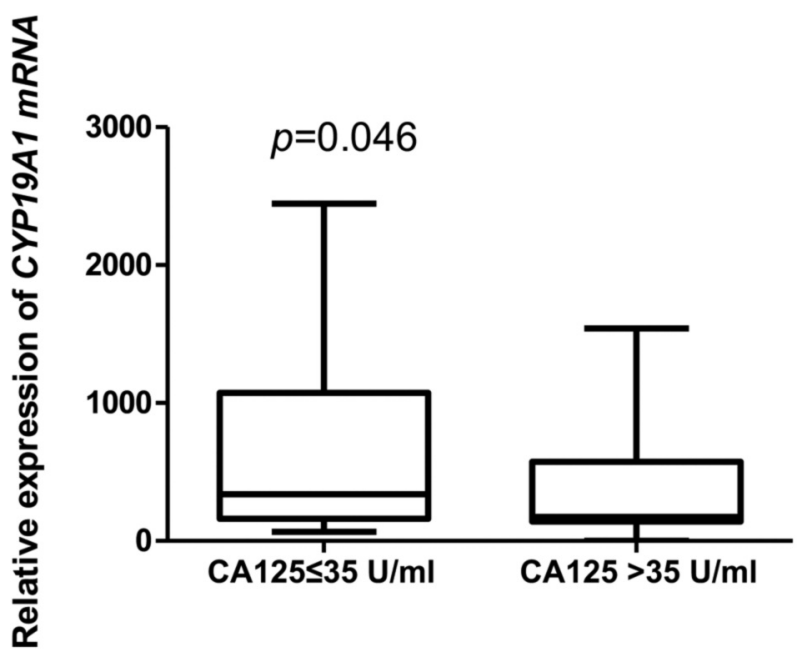

Figure 4. Relative gene expression of cytochrome P450 family 19 subfamily A member (CYP19A1) according to the level of the marker cancer antigen 125 (CA125).

Van Kaam et al. demonstrated that methyl-CpG-binding proteins, such as MBD1 and MeCP2, which contain the methyl-CpG-binding N-terminal domain and the transcription inhibition domain on the carboxyl terminus, were not bound with the hypermethylated region of a $\mathrm{CpG}$ island in eutopic tissues (19). It may explain the 'muting' of aromatase expression in eutopic endometrium. The treatment of endometrial stromal cells with 5-azadeoxycytidine (an irreversible inhibitor of DNA methyltransferase, which is necessary to maintain the status of genomic DNA methylation) induces the expression of aromatase (18).

Demethylation of CpG islands in CYP19A1 gene may be significant for the control of aromatase levels, although other explanations are also possible, since 5-aza-deoxycytidine changes the expression levels of a broad spectrum of genes which may either indirectly or directly affect aromatase expression (19).

Maia et al. obtained results clearly indicating that CYP19A1 expression was not strictly associated with endometriosis (20). The researchers carried out their studies to see whether the expression of aromatase in eutopic endometrium correlated with the presence of endometriosis and its clinical staging in 106 women of reproductive age and with symptoms of dysmenorrhoea and infertility. The patients were submitted to laparoscopy and hysteroscopy. A control group consisted of 16 patients with asymptomatic endometriosis. The results of the study demonstrated that aromatase expression in the endometrium was associated with the occurrence of dysmenorrhoea and infertility, regardless of whether endometriosis was present or not (20).

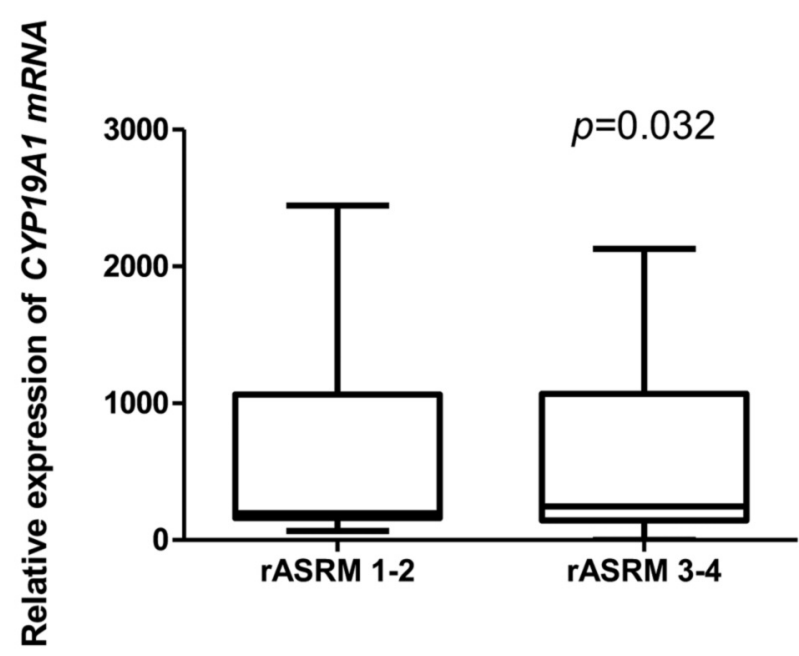

Figure 5. Relative gene expression (in peritoneal endometriosis) of cytochrome P450 family 19 subfamily A member (CYP19A1) according to the Revised American Society for Reproductive Medicine(rASRM) classification of endometriosis.

Table IV. Relative gene expression of cytochrome P450 family 19 subfamily A member (CYP19A1) with regard to the number of pregnancies and deliveries.

\begin{tabular}{lcc}
\hline & $\begin{array}{c}\text { Pregnancies }=0 ; \\
\text { Deliveries }=0\end{array}$ & $\begin{array}{c}\text { Pregnancies }>0 ; \\
\text { Deliveries }>0\end{array}$ \\
\hline Number of specimens & 38 & 24 \\
Mean \pm SD & $685.4 \pm 627.4$ & $504.2 \pm 489.9$ \\
& $(0-2,446)$ & $(94.16-2,128)$ \\
\hline
\end{tabular}

Mann-Whitney test, $p=0.031$.

The results of this study, concerning the analysis of ESR2 and CYP19A1 genes, unveil certain correlations of their expression with endometriosis. It should, however, be emphasised that this study involved a numerically small population (100 patients) and thus requires continuation on much larger study groups. Taking into account the significance of the obtained results, such studies should be continued. The results, obtained in the study, contribute to better knowledge of and information on the molecular mechanisms which support the development of endometriosis. The study pointed out differences in the expression levels of the studied genes between the studied groups of patients, which may potentially foster the development of the condition. In consideration of the rather small number of studies on the expression of CYP19A1 and ESR2 genes in patients with endometriosis from the Polish population, these findings may bring real added value, broadening the knowledge of the effects of genetic factors on the development of endometriosis. 
Determining the relationships between ESR2 and CYP19A1 gene expression and endometriosis may help design and develop new therapeutic concepts and strategies for this disease. Studies on gene expression aspects are likely to constitute a prima facie target of major concern regarding personalised therapy.

\section{Conclusion}

A significant increase of ESR2 gene expression was observed in the group of women with endometriosis, which may indicate a role of this factor in the pathogenesis of endometriosis. The lack of statistically significant difference in CYP19A1 gene expression in the study group versus the control indicates no participation of the gene in the pathogenesis of endometriosis. A higher expression of ESR2 gene was demonstrated in the group of patients with endometrial nodules of abdominal walls. This shows a significant role of ESR2 gene in the pathogenesis of this form of endometriosis. In the group of patients with endometrial ovarian cysts and peritoneal endometriosis, the levels of CYP19A1 expression were associated with the rASRM clinical staging of endometriosis. In the case of nulliparous patients with endometrial cysts, a statistically significant positive correlation was demonstrated with CYP19A gene expression.

\section{Declarations}

Ethics approval and consent to participate. This work was supported by the Institute of Polish Mother's Memorial Hospital, Lodz, Poland from the Statutory Development Fund. All procedures performed in studies involving human participants were in accordance with the ethical standards of the institutional and/or national research committee and with the 1964 Helsinki declaration and its later amendments or comparable ethical standards. All the study participants gave their written-informed consent.

\section{Funding}

This work was supported by the Polish Ministry of Science and Higher Education, Polish Mother's Memorial Hospital Research Institute Young Researcher Internal Grant (No. 2016/VI/13-MN).

\section{Conflicts of Interest}

The Authors declare no conflicts of interest in regard to this study.

\section{Authors' Contributions}

Conceived and designed the study: TS and BS. Performed the experiments - case group: MB and EF. Case group design and collection: TS, HR, KS, BK, MS and BM. Performed the study control group: $\mathrm{MB}$ and EF. Analysed data: BS. Contributed reagents/materials/analysis tools: $\mathrm{MB}$ and $\mathrm{EF}$. Contributed to the writing of article: BS and TS. All Authors approved the final article.

\section{Acknowledgements}

Authors acknowledge the financial support provided by the Institute of Polish Mother's Memorial Hospital, Lodz, Poland, to conduct the study.

\section{References}

1 Parasar P, Ozcan P and Terry KL: Endometriosis: Epidemiology, diagnosis and clinical management. Curr Obstet Gynecol Rep 6: 34-41, 2017. PMID: 29276652. DOI: 10.1007/s13669-017-0187-1

2 Defrère S, Lousse JC, González-Ramos R, Colette S, Donnez J and Van Langendonckt A: Potential involvement of iron in the pathogenesis of peritoneal endometriosis. Mol Hum Reprod 14: 377-385, 2008. PMID: 18508952. DOI: 10.1093/molehr/gan033

3 Othman Eel-D, Hornung D, Salem HT, Khalifa EA, El-Metwally $\mathrm{TH}$ and Al-Hendy A: Serum cytokines as biomarkers for nonsurgical prediction of endometriosis. Eur J Obstet Gynecol Reprod Biol 137: 240-246, 2008. PMID: 17582674. DOI: 10.1016/j.ejogrb.2007.05.001

4 Mihalyi A, Gevaert O, Kyama CM, Simsa P, Pochet N, De Smet F, De Moor B, Meuleman C, Billen J, Blanckaert N, Vodolazkaia A, Fulop V and D'Hooghe TM: Non-invasive diagnosis of endometriosis based on a combined analysis of six plasma biomarkers. Hum Reprod 25: 654-664, 2010. PMID: 20007161. DOI: 10.1093/humrep/dep425

5 Meinhardt U and Mullis PE: The aromatase cytochrome P-450 and its clinical impact. Horm Res 57: 145-152, 2002. PMID: 12053085. DOI: $10.1159 / 000058374$

6 De Abreu LG, Silveira VS, Scrideli C, Ramos ES, Dos Reis RM, Ferriani RA and Silva de Sa MF: Endometriosis does not alter aromatase gene expression (CYP19A1) in mural lutein-granulosa cells of women undergoing assisted reproduction techniques - A pilot study. J Endometr 3: 171-182, 2011. DOI: 10.5301/ JE.2012.9070

7 Bulun SE, Monsavais D, Pavone ME, Dyson M, Xue Q, Attar E, Tokunaga $\mathrm{H}$ and $\mathrm{Su}$ EJ: Role of estrogen receptor- $\beta$ in endometriosis. Semin Reprod Med 30: 39-45, 2012. PMID: 22271293. DOI: $10.1055 / \mathrm{s}-0031-1299596$

8 Han SJ, Jung SY, Wu SP, Hawkins SM, Park MJ, Kyo S, Qin J, Lydon JP, Tsai SY, Tsai MJ, DeMayo FJ and O'Malley BW: Estrogen receptor $\beta$ modulates apoptosis complexes and the inflammasome to drive the pathogenesis of endometriosis. Cell 163: 960-974, 2015. PMID: 26544941. DOI: 10.1016/j.cell. 2015.10.034

9 Wei C, Mei J, Tang L, Liu Y, Li D, Li M and Zhu X: 1-Methyltryptophan attenuates regulatory T-cells differentiation due to the inhibition of estrogen-IDO1-MRC2 axis in endometriosis. Cell Death Dis 7: e2489, 2016. PMID: 27906184. DOI: 10.1038/ cddis. 2016.375

10 Huhtinen K, Ståhle M, Perheentupa A and Poutanen M: Estrogen biosynthesis and signaling in endometriosis. Mol Cell Endocrinol 358: 146-154, 2012. PMID: 21875644. DOI: 10.1016/j.mce.2011.08.022

11 Colón-Caraballo M, García M, Mendoza A and Flores I: Human endometriosis tissue microarray reveals site-specific expression of estrogen receptors, progesterone receptor, and Ki67. Appl Immunohistochem Mol Morphol 27: 491-500, 2019. PMID: 29629944. DOI: 10.1097/PAI.0000000000000663 
12 Yilmaz BD and Bulun SE: Endometriosis and nuclear receptors. Hum Reprod Update 25: 473-485, 2019. PMID: 30809650. DOI: 10.1093/humupd/dmz005

13 Yi K, Yang L, Lan Z and Xi M: The association between CYP19 polymorphism and endometriosis risk: A system review and meta-analysis. Eur J Obstet Gynecol Reprod Biol 199: 42-48, 2016. PMID: 26897397. DOI: 10.1016/j.ejogrb.2016.01.010

14 Revised American Society for Reproductive Medicine classification of endometriosis: 1996. Fertil Steril 67: 817-821, 1997. PMID: 9130884. DOI: 10.1016/s0015-0282(97)81391-x

15 Maekawa R, Mihara Y, Sato S, Okada M, Tamura I, Shinagawa M, Shirafuta Y, Takagi H, Taketani T, Tamura H and Sugino N: Aberrant DNA methylation suppresses expression of estrogen receptor 1 (ESR1) in ovarian endometrioma. J Ovarian Res 12: 14, 2019. PMID: 30728052. DOI: 10.1186/s13048-019-0489-1

16 Hosseini E, Mehraein F, Shahhoseini M, Karimian L, Nikmard $\mathrm{F}$, Ashrafi M, Afsharian $\mathrm{P}$ and Aflatoonian R: Epigenetic alterations of CYP19A1 gene in Cumulus cells and its relevance to infertility in endometriosis. J Assist Reprod Genet 33: 110513, 2016. PMID: 27167072. DOI: 10.1007/s10815-016-0727-z

17 Izawa M, Taniguchi F, Uegaki T, Takai E, Iwabe T, Terakawa N and Harada T: Demethylation of a non-promoter cytosinephosphate-guanine island in the aromatase gene may cause the aberrant up-regulation in endometriotic tissues. Fertil Steril 95: 33-39, 2011. PMID: 20655525. DOI: 10.1016/j.fertnstert. 2010.06 .024
18 van Kaam KJ, Delvoux B, Romano A, D’Hooghe T, Dunselman GA and Groothuis PG: Deoxyribonucleic acid methyltransferases and methyl-CpG-binding domain proteins in human endometrium and endometriosis. Fertil Steril 95: 1421-1427, 2011. PMID: 21316665. DOI: 10.1016/j.fertnstert.2011.01.031

19 Izawa M, Harada T, Taniguchi F, Ohama Y, Takenaka Y and Terakawa N: An epigenetic disorder may cause aberrant expression of aromatase gene in endometriotic stromal cells. Fertil Steril 89: 1390-1396, 2008. PMID: 17662285. DOI: 10.1016/j.fertnstert.2007.03.078

20 Maia H Jr, Haddad C and Casoy J: Correlation between aromatase expression in the eutopic endometrium of symptomatic patients and the presence of endometriosis. Int J Womens Health 4: 61-65, 2012. PMID: 22393305. DOI: 10.2147/IJWH.S29154

Received March 4, 2020

Revised March 23, 2020

Accepted March 27, 2020 